\title{
Commentary: Casting near-infrared light on cerebral oxygen economy in neonatal congenital heart disease
}

John P. Scott, MD

From Divisions of Pediatric Anesthesiology and Pediatric Critical Care, Pediatric Liver Transplant Anesthesia, Children's Hospital of Wisconsin, Milwaukee, Wis; Sections of Pediatric Anesthesiology and, Pediatric Critical Care, Department of Anesthesiology and Pediatrics, Medical College of Wisconsin, Milwaukee, Wis. Disclosures: Author has nothing to disclose with regard to commercial support.

Received for publication Sept 17, 2019; revisions received Sept 17, 2019; accepted for publication Sept 18, 2019; available ahead of print Nov 8, 2019.

Address for reprints: John P. Scott, MD, 9000 W Wisconsin Ave, PO Box 1997, Milwaukee, WI 53201-1997 (E-mail: scottjake@mcw.edu).

J Thorac Cardiovasc Surg 2020;159:2022-3

$0022-5223 / \$ 36.00$

Copyright (c) 2019 by The American Association for Thoracic Surgery

https://doi.org/10.1016/j.jtcvs.2019.09.038

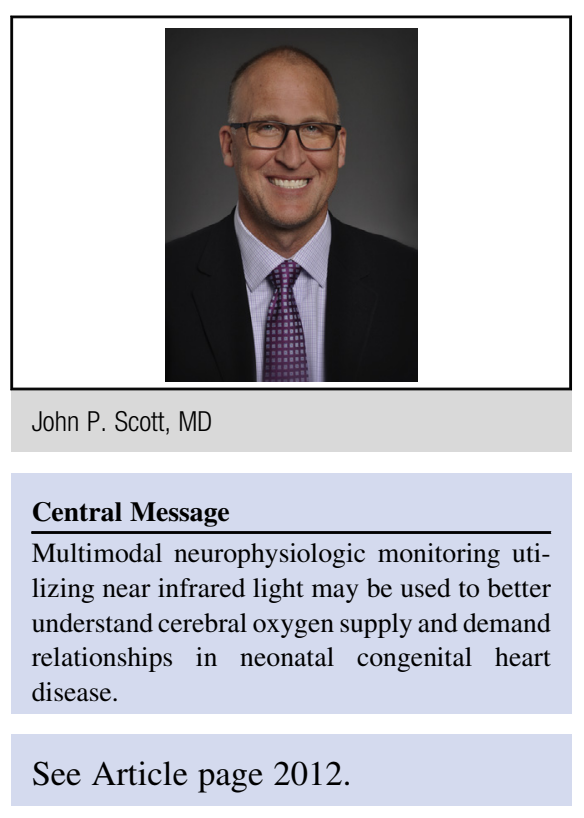

Neonates with congenital heart disease (CHD) who require cardiopulmonary bypass may have disease-related and procedure-related disturbances in cerebral oxygen economy, resulting in hypoxic ischemic injuries and abnormal neurodevelopmental outcomes. Advanced neurophysiologic monitoring with near-infrared light may be used to assess cerebral oxygen delivery and consumption. Near-infrared spectroscopy (NIRS), most commonly used as a continuous-wave modality, generates a cerebral tissue oxygen saturation that is highly correlated with jugular venous oxygen saturation. ${ }^{1,2}$ Reduced cerebral tissue oxygen saturation has been linked to states of cerebral oxygen debt and adverse neurodevelopmental outcomes. ${ }^{3-6}$ Frequency domain NIRS represents an alternative methodology with improved accuracy for determination of absolute tissue saturation. ${ }^{7}$ Diffuse correlation spectroscopy measures scattering of near-infrared light by red blood cells traveling through an optical field, generating a cerebral blood flow index $(\mathrm{CBFi}){ }^{8}$ By using the Fick equation and available clinical data (hemoglobin and arterial oxygen saturation), cerebral tissue oxygen saturation and CBFi measurements enable calculation of the cerebral oxygen extraction fraction $(\mathrm{OEF})$ and the cerebral metabolic rate, providing a quantitative assessment of cerebral oxygen supply and demand. ${ }^{8-10}$

In the current issue of the Journal, Cheng and colleagues ${ }^{9}$ report the results of a prospective observational study in neonates comparing frequency domain NIRS- and diffuse correlation spectroscopy-derived variables of cerebral hemodynamics and oxygen metabolism in healthy control patients and 3 CHD groups ( 2 ventricle, transposition of the great arteries [TGA], and single-ventricle anatomy [SV]). Comparisons were performed between the control group and the CHD groups preoperatively, and among the CHD groups preoperatively and postoperatively. Relative to control subjects, neonates with CHD exhibited significant differences in cerebral hemodynamics and oxygen metabolism. Notably, neonates with SV had lower preoperative $\mathrm{CBFi}$, whereas neonates with both TGA and SV had increased preoperative OEF. One important finding within the CHD groups revealed a reduction in OEF after TGA repair. Cheng and colleagues ${ }^{9}$ hypothesized that increased preoperative OEF in neonates with TGA and SV might be a compensatory mechanism and that reduced calculated ratio of CBFi to cerebral metabolic rate in neonates with SV might be secondary to abnormal prenatal cerebral development.

Limitations of this work include the small sample size and multiple comparisons. More importantly, cerebral frequency domain NIRS and diffuse correlation spectroscopic measurements were performed intermittently, yet the real utility of oximetric technology lies in the ability to perform continuous, noninvasive measurements. No description of patient state during assessments was provided, despite evidence of wide state-dependent variation in cerebral NIRS values. ${ }^{11}$ The bypass strategy involved moderate to deep hypothermia with $\mathrm{pH}$-stat blood gas management, all of which have been linked to impaired cerebral autoregulation, potentially affecting postoperative measurements. ${ }^{12-14}$ Finally, there was little discussion of important perioperative ventilatory, vasoactive, or transfusion management strategies, which affect cerebral oxygen delivery and metabolism.

Nevertheless, this thought-provoking study provides a framework for continued exploration of multimodal 
neurophysiologic monitoring incorporating near-infrared light to detect abnormalities in cerebral oxygen economy in CHD. Future investigations must focus on ways to incorporate continuous monitoring, which would allow targeted interventions to modify cerebral oxygen debt and associated adverse outcomes in this at-risk population.

\section{References}

1. Abdul-Khaliq H, Troitzsch D, Berger F, Lange PE. [Regional transcranial oximetry with near infrared spectroscopy (NIRS) in comparison with measuring oxygen saturation in the jugular bulb in infants and children for monitoring cerebral oxygenation]. Biomed Tech (Berl). 2000;45:328-32. German.

2. Nagdyman N, Fleck T, Schubert S, Ewert P, Peters B, Lange PE, et al. Comparison between cerebral tissue oxygenation index measured by near-infrared spectroscopy and venous jugular bulb saturation in children. Intensive Care Med. 2005;31:846-50.

3. Hoffman GM, Brosig CL, Mussatto KA, Tweddell JS, Ghanayem NS. Perioperative cerebral oxygen saturation in neonates with hypoplastic left heart syndrome and childhood neurodevelopmental outcome. J Thorac Cardiovasc Surg. 2013;146:1153-64.

4. Hansen JH, Rotermann I, Logoteta J, Jung O, Dütschke P, Scheewe J, et al. Neurodevelopmental outcome in hypoplastic left heart syndrome: impact of perioperative cerebral tissue oxygenation of the Norwood procedure. J Thorac Cardiovasc Surg. 2016;151:1358-66.

5. Sood ED, Benzaquen JS, Davies RR, Woodford E, Pizarro C. Predictive value of perioperative near-infrared spectroscopy for neurodevelopmental outcomes after cardiac surgery in infancy. J Thorac Cardiovasc Surg. 2013;145:438-45.e1 discussion 444-5.

6. Kurth CD, McCann JC, Wu J, Miles L, Loepke AW. Cerebral oxygen saturationtime threshold for hypoxic-ischemic injury in piglets. Anesth Analg. 2009;108: 1268-77.

7. Kurth $\mathrm{CD}$, Thayer WS. A multiwavelength frequency-domain near-infrared cerebral oximeter. Phys Med Biol. 1999;44:727-40.

8. Buckley EM, Parthasarathy AB, Grant PE, Yodh AG, Franceschini MA. Diffuse correlation spectroscopy for measurement of cerebral blood flow: future prospects. Neurophotonics. 2014;1:011009.

9. Cheng HH, Ferradal SL, Vyas R, Wigmore D, McDavitt E, Soul JS, et al. Abnormalities in cerebral hemodynamics and changes with surgical intervention in neonates with congenital heart disease. J Thorac Cardiovasc Surg. 2020;159: 2012-21.

10. Spiess BD, Tuman KJ, McCarthy RJ, Logas WG, Lubenow TR, Williams J, et al Oxygen consumption and mixed venous oxygen saturation monitoring during orthotopic liver transplantation. J Clin Monit. 1992;8:7-11.

11. Bernal NP, Hoffman GM, Ghanayem NS, Arca MJ. Cerebral and somatic near-infrared spectroscopy in normal newborns. J Pediatr Surg. 2010;45: 1306-10.

12. Ono M, Brady K, Easley RB, Brown C, Kraut M, Gottesman RF, et al. Duration and magnitude of blood pressure below cerebral autoregulation threshold during cardiopulmonary bypass is associated with major morbidity and operative mortality. J Thorac Cardiovasc Surg. 2014;147:483-9.

13. Brady KM, Mytar JO, Lee JK, Cameron DE, Vricella LA, Thompson WR, et al. Monitoring cerebral blood flow pressure autoregulation in pediatric patients during cardiac surgery. Stroke. 2010;41:1957-62.

14. Joshi B, Ono M, Brown C, Brady K, Easley RB, Yenokyan G, et al. Predicting the limits of cerebral autoregulation during cardiopulmonary bypass. Anesth Analg. 2012;114:503-10. 